\section{Artist Featured in Volume 3 IJMS: Anto Sg}

Huy Ming Lim.'

Gracing the covers of the issues in the third volume of the International Journal of Medical Students are the inspiring artworks of Anto Sg (Agus Sugianto), an activist and advocate for people with psychosocial disabilities in Indonesia. Himself a victim of the local practice of pasung, which refers to the physical restraint and confinement of people with mental illness with shackles, ropes, wooden stocks and cages. Anto now breaks free from the shackles that once consumed him and aspires to empower other people with mental disabilities to achieve the same.

Growing up in an impoverished family in Tulungagung, East Java, Anto was repeatedly pulled away from his childhood dream of becoming an English teacher by reality. Refusing to yield to his fate, he enrolled himself in a local university and began working night shifts to pay for his tuition fees and living expenses. Despite the hard work, his dream became a distant reality when his lost all of his savings and posses-

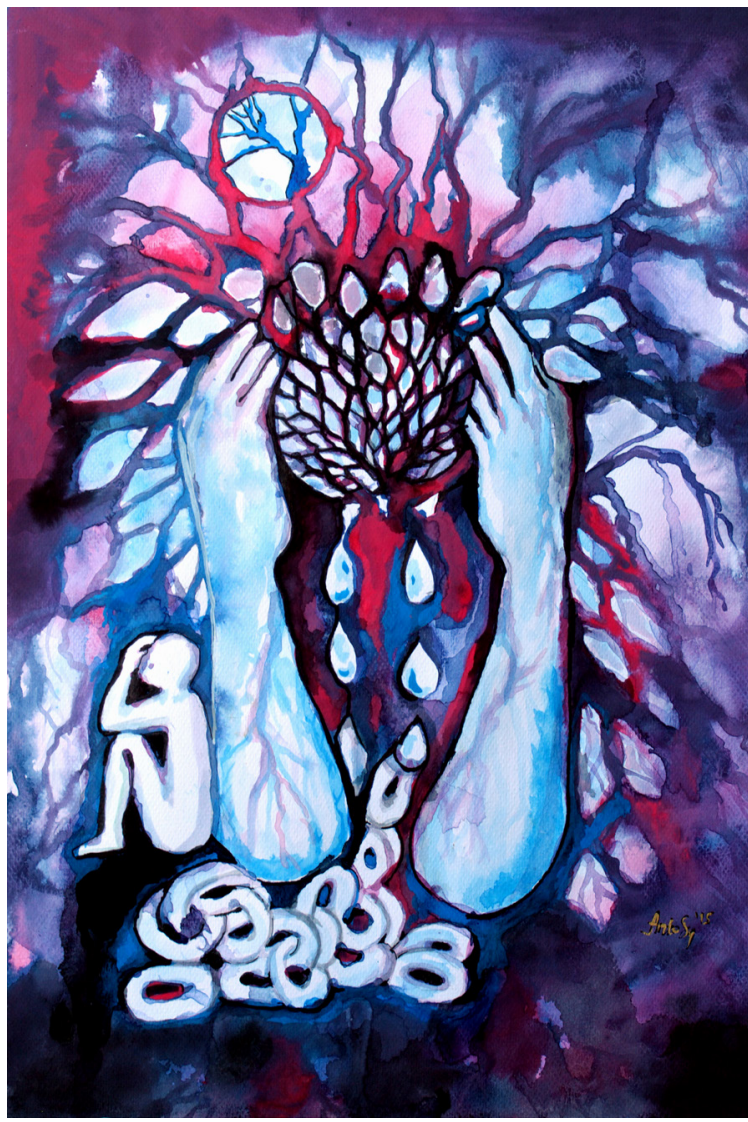

Scene 1. Shattered Dignity. "I felt like I did not exist anymore. I had no dignity. It had been torn apart by stigmatization. Chains really destroyed me. I was falling into a deeper depression". Cover of IJMS Volume 3 Issue 1. sions in a scam. His hopes were shattered, and he sunk into a deep depression. He began to show symptoms of affective disorders and psychosis. Not knowing how to deal with his mental condition, his family resorted to the dehumanizing practice of shackling every time he was unwell, each lasting from several days to several months, stripping him of his freedom and dignity.

Today, with his own determination and help from others, Anto has reintegrated into the community and become a self-taught artist, a Batik designer, and a university student once again, majoring in his favorite subject-English language teachingand expecting to graduate in August 2016. Sharing his experiences through paintings and storytelling, he is now a frequent speaker at local and national mental health and human rights events. He has been interviewed by BBC News, the top-rated national television show "Kick Andy", and a number of national and international magazines. Through Komunitas Peduli Skizofrenia, Bipolar Care Indonesia, and Harmony in Diversity, alliances and support groups for people living with mental disabilities, he has joined hands with other mental health activists to fight against the inhumane practice of pasung and eradicate the stigma and discrimination against people with mental health disabilities.

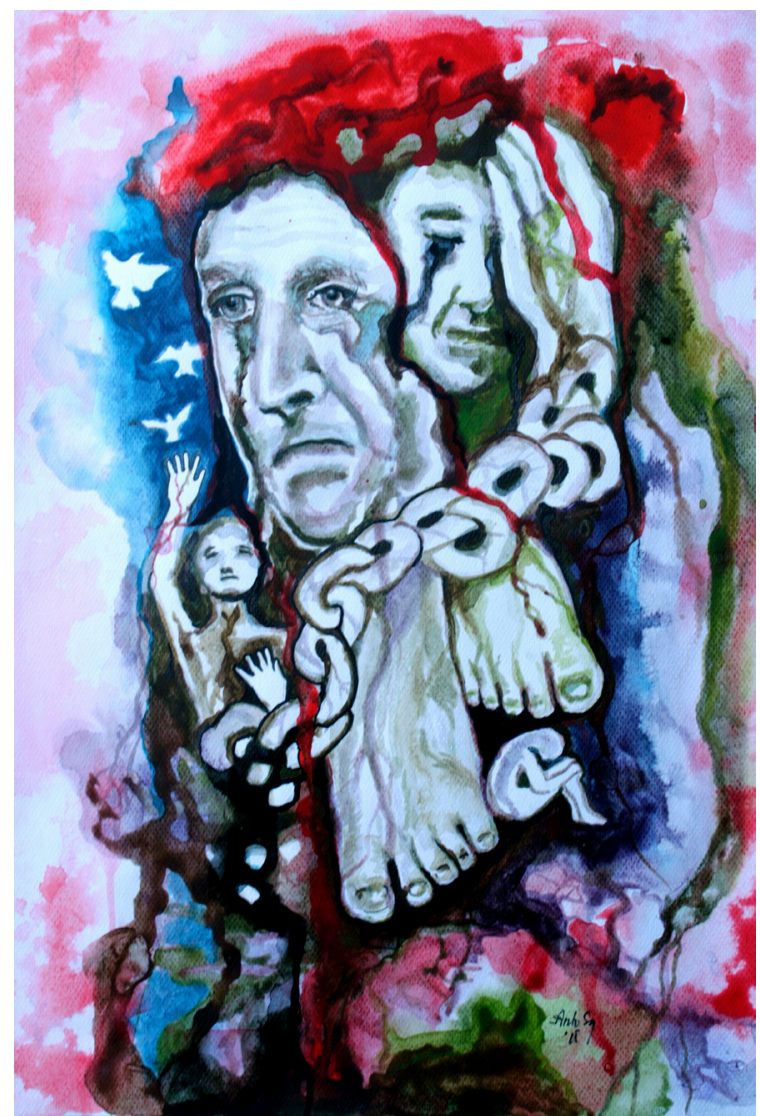

Scene 2. Pain in Shackles. "The true feelings of my pasung experience. It tortured my body and soul. I was in enormous pain and could barely breathe because of the burden in my heart. Pasung victims do really feel this. Freedom was so far away to be reached in my perspective at that point. I transposed these feelings into a painting. I was crying out but nobody cared. I felt hopeless". Cover of IJMS Volume 3 Issue 2.

${ }^{1}$ Healthcare Statistics Unit, National Clinical Research Centre, National Institutes of Health, Ministry of Health, Malaysia.

Email: limhuyming@gmail.com 
Anto is also the subject of the ethnographic documentary "Breaking the Chains: Anto's Story", which he co-directed with Dr. Erminia Colucci from Queen Mary University of London in collaboration with the Granada Centre for Visual Anthropology (The University of Manchester, UK) and the Centre for International Mental Health (The University of Melbourne, Australia). The "Breaking the Chains" series has been screened at the World Health Organization headquarters in Geneva on 2013 World Mental Health Day and at other international mental health conferences and events (excerpts from the films can be viewed at http://movie-ment.org/breakingthechains). In December 2014, Anto won the First Prize in the International Essay Competition on Arts and Mental Health organized by the World Association of Cultural Psychiatry with his firsthand account of his pasung experiences. The winning essay was recently published in the latest issue of the World Cultural Psychiatry Research Review. ${ }^{1}$

To be treated with dignity is a fundamental right of every human being, and no one shall be subjected to inhuman or degrading treatment, including people with mental disabilities. The International Journal of Medical Student is honored to feature the "Breaking the Shackles: Anto's Journey" collection, which Anto created exclusively for us, as our issue covers for Volume $3 .^{2}$ On behalf of the Editorial Board of the International Journal of Medical Students and all our readers around the world, we thank you, Anto, for your inspiring stories and artworks! We hope you will continue to inspire the world with your perseverance and resilience for years to come!

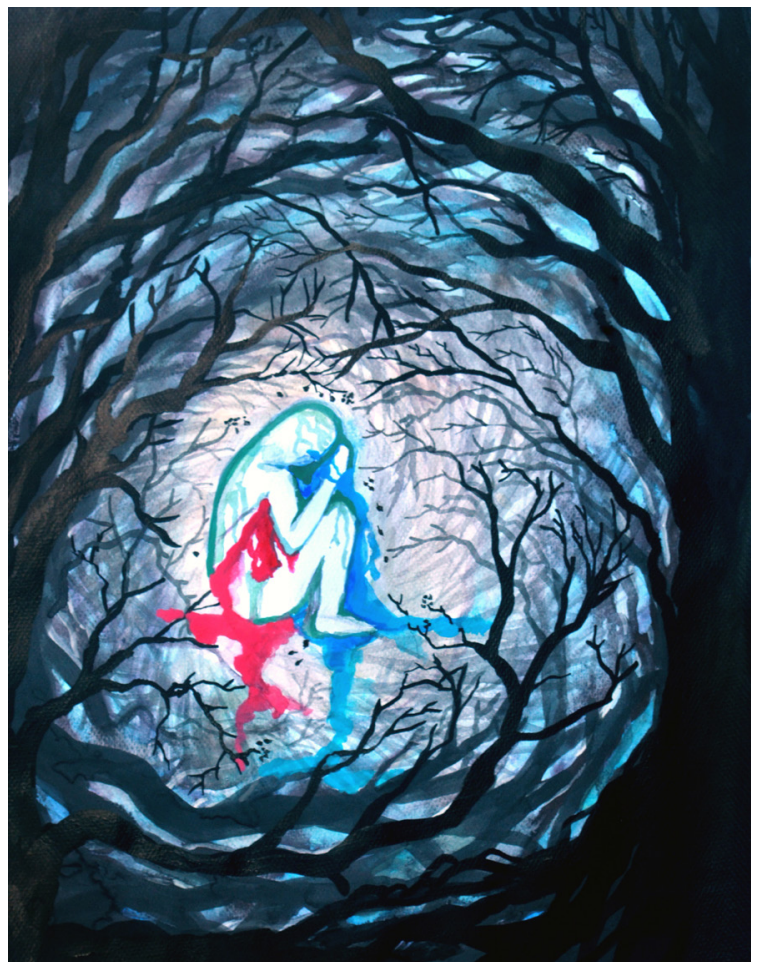

Scene 3. Bleeding Misery. "I was at the bottom of misery. I was deeply depressed, being stigmatized and labeled as "crazy". My heart was like a bleeding wound. I had no future. I was desperate. Tears drained down. I was covered with a dark trauma of pasung. This was me, at the lowest point of my life". Not included in the covers.

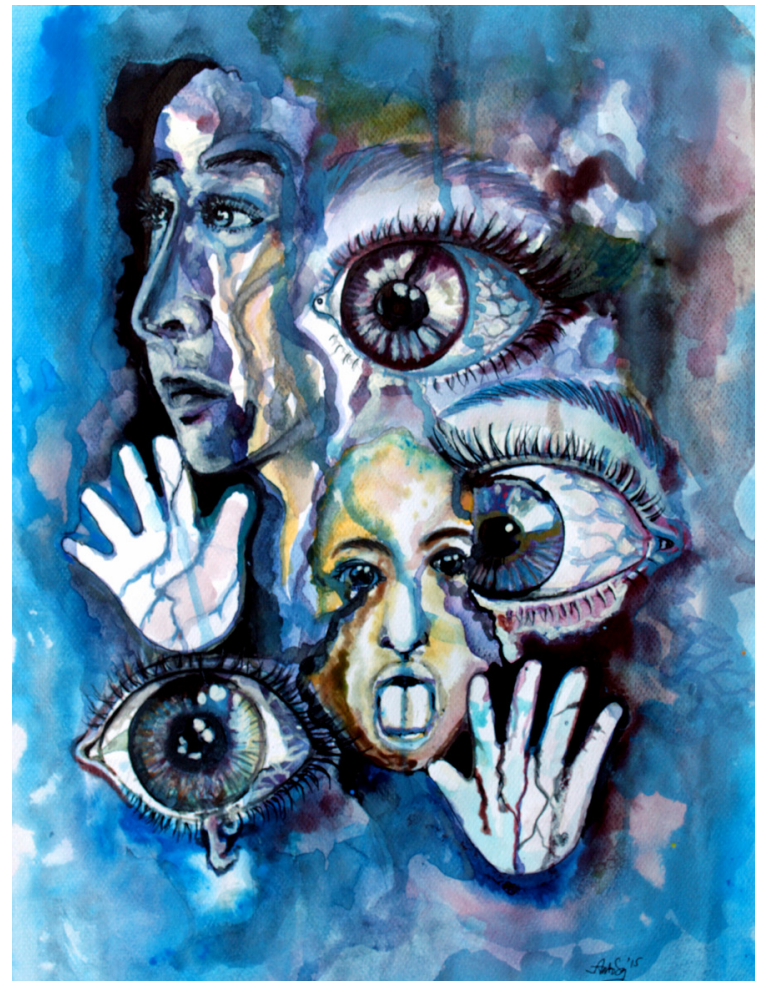

Scene 4. Stigma and Rejection. "I felt so lost. People started to treat me differently. They used to say hello but not anymore. Some of them looked away when they saw me. When they did look at me, it was with strange eyes. The feelings of sadness haunted me". - Pasung journey, Anto Sg, 1999. Cover of IIMS Volume 3 Issue 3.

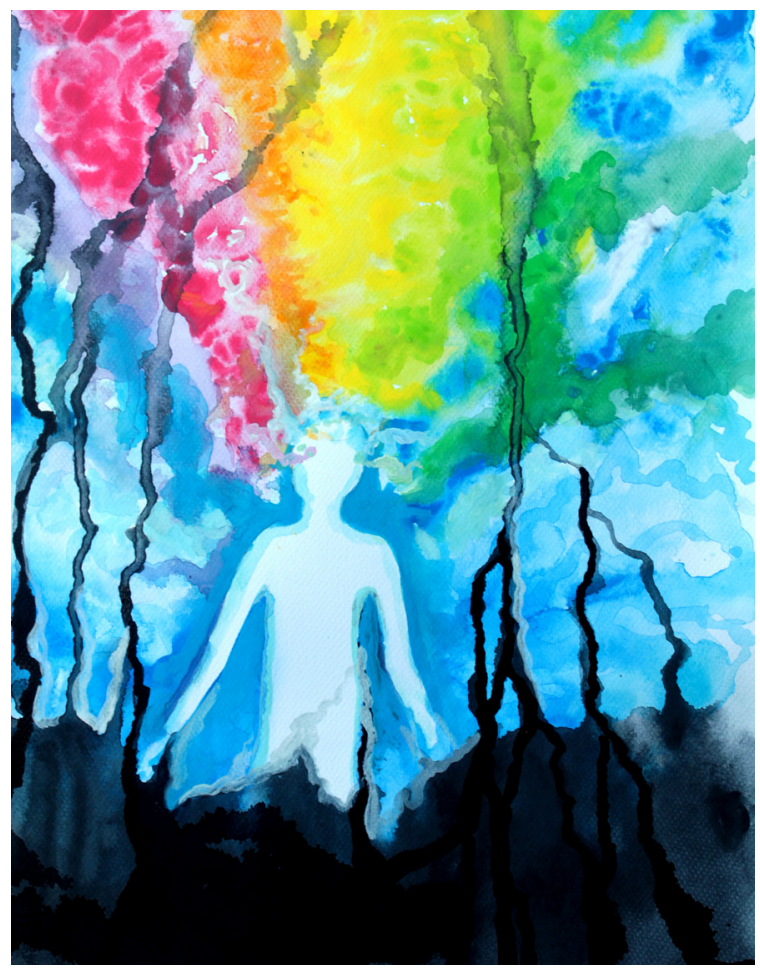

Scene 6. Powerful Minds. "Powerful mind, creativity, and positive thoughts give me the courage to face the future and leave all the darkness behind. I manage to keep moving on, coping with struggles in this new life. Falling is so that we can get up and rise again. Never give up". Not included in the covers. 


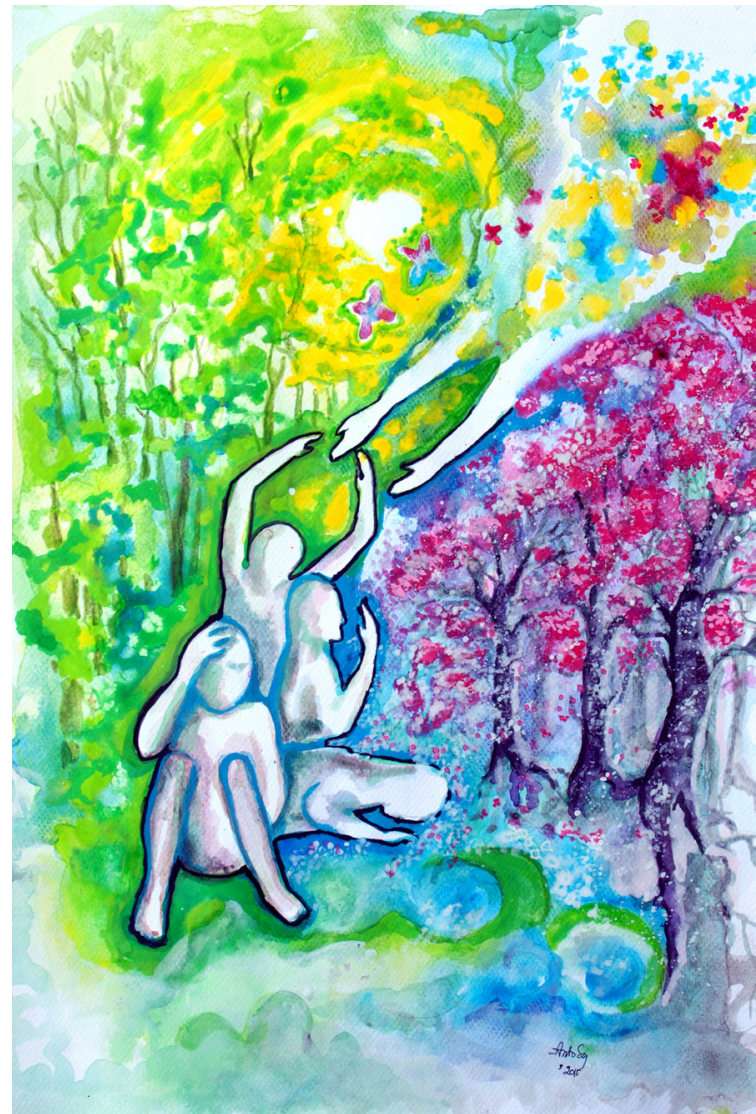

Scene 5. Embracing Hope and Life. "Finally, after a long struggle, managed to find strength through self-motivation, introspections, and faith. I assembled pieces of my life back into a new form. New hope began. I survived again. My prayers are answered. Gratefulness is everything".

Cover of IJMS Vol 3 Supplement 1.

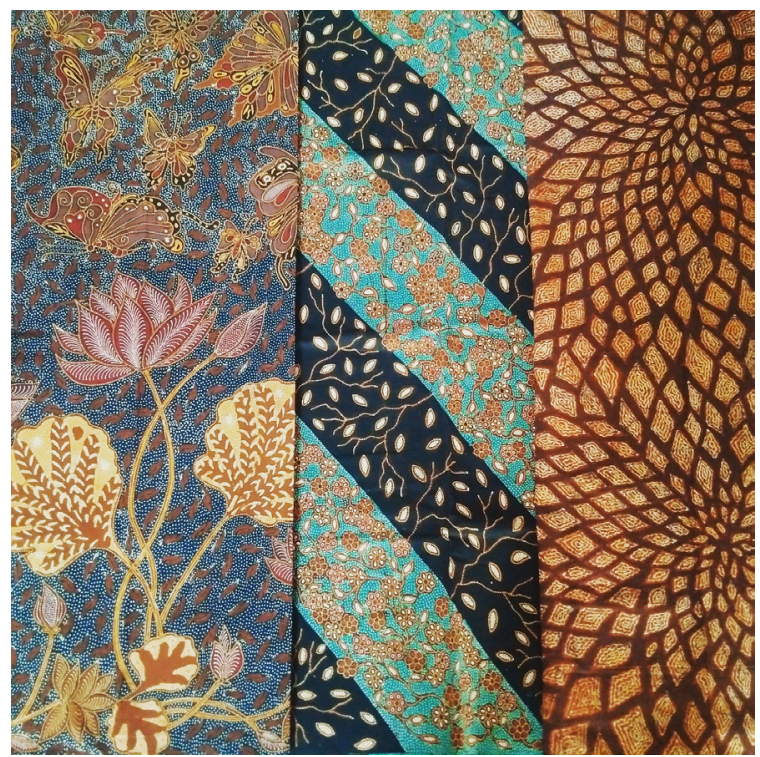

Supplementary images: Anto's paints.

Not included in the covers.

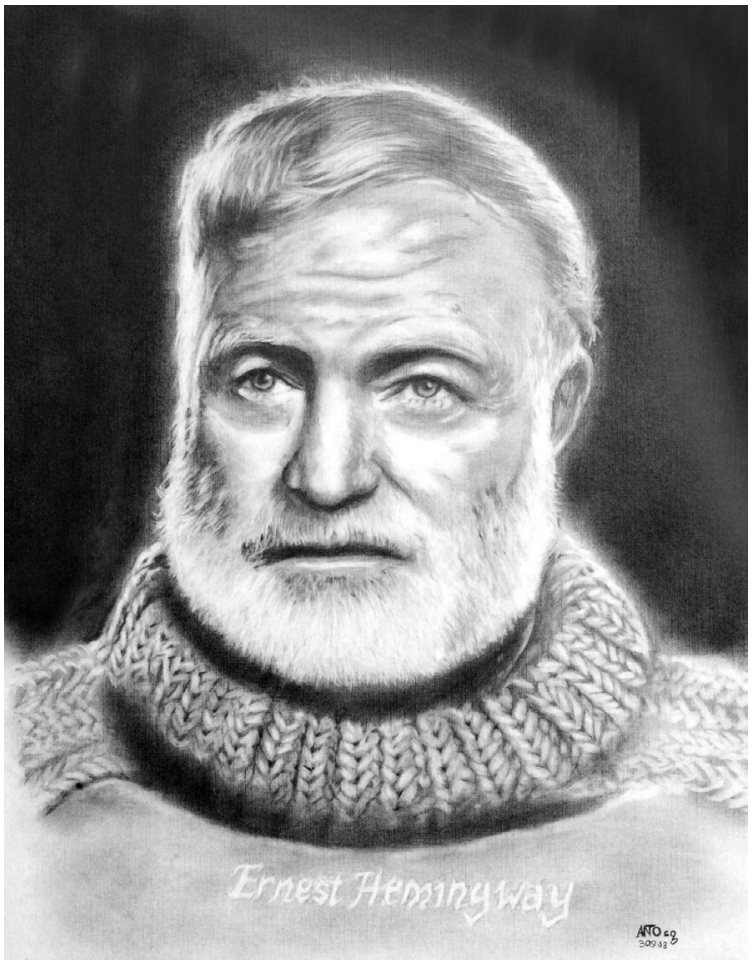

Supplementary images: Other Anto's paints.

Not included in the covers.

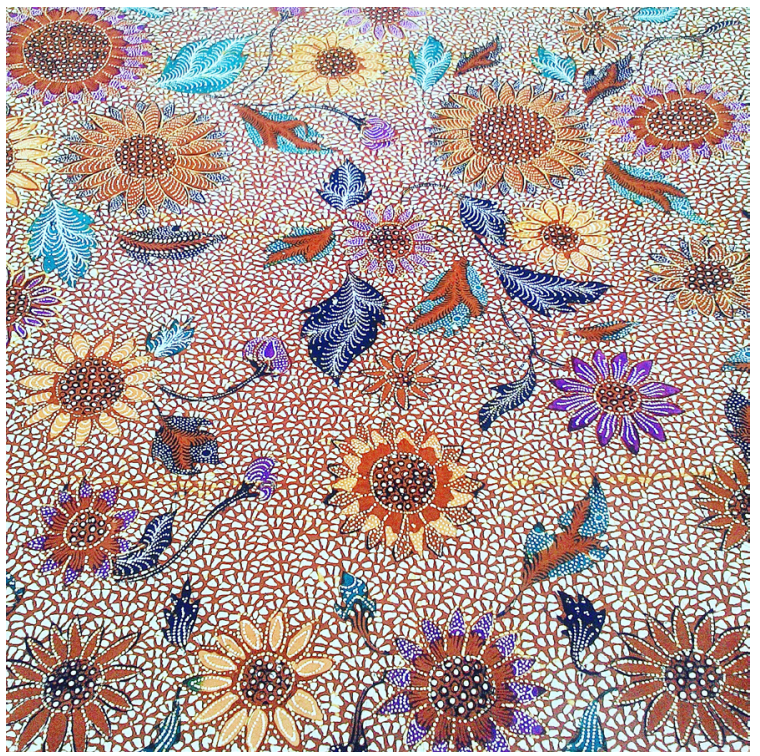

Supplementary images: Anto's paints.

Not included in the covers.

\section{References}

1. Anto S, Colucci E. Free from pasung: a story of chaining and freedom in Indonesia told through painting, poetry and narration. World Cult Psychiatry Res Rev. 2015 Sep-Dec;10(34):149-67.

2. Bonilla-Escobar FJ, Ming Lim H. A call for action for mental health: Medical students and physicians' roles. Int J Med Students. 2015 Sep-Dec;3(3):121-3.

Cite as: Ming Lim H. Artist Featured in Volume 3 IJMS: Anto Sg. Int J Med Students. 2015 Sep-Dec;3(3):172-4. 